\title{
HYDROTHERMAL SYNTHESIS OF IRON OXIDE PHOTO-FENTON CATALYSTS: THE EFFECT OF PARAMETERS ON MORPHOLOGY, PARTICLE SIZE AND CATALYTIC EFFICIENCY
}

\author{
PASTRANA-MARTINEZ L.M. ${ }^{1}$ \\ GOMES H.T. ${ }^{1,2}$ \\ DRAZIC G. ${ }^{3,4}$ \\ FARIA J.L. ${ }^{1}$ \\ SILVA A.M.T. ${ }^{1, *}$
}

\author{
${ }^{1}$ Laboratory of Catalysis and Materials - Associate Laboratory LSRE/LCM \\ Faculdade de Engenharia, Universidade do Porto \\ Rua Dr. Roberto Frias, 4200-465 Porto, Portugal \\ ${ }^{2}$ School of Technology and Management \\ Polytechnic Institute of Bragança, Campus de Santa Apolónia \\ 5300-857 Bragança, Portugal \\ ${ }^{3}$ Department of Nanostructured Materials \\ Jozef Stefan Institute, Jamova 39, SI-1000 Ljubljana, Slovenia \\ ${ }^{4}$ Laboratory for Materials Chemistry, National Institute of Chemistry \\ Hajdrihova 19, SI-1000 Ljubljana, Slovenia
}

Received: 21/01/2014

Accepted: 25/02/2014

Available online: 11/03/2014
* to whom all correspondence should be addressed: e-mail: adrian@fe.up.pt

\begin{abstract}
Iron oxide materials were synthesized by an easy and rapid hydrothermal method using different iron precursors $\left(\mathrm{FeCl}_{3} \cdot 6 \mathrm{H}_{2} \mathrm{O}\right.$, $\mathrm{Fe}\left(\mathrm{NO}_{3}\right)_{3} \cdot 9 \mathrm{H}_{2} \mathrm{O}$ and $\left.\mathrm{K}_{4} \mathrm{Fe}(\mathrm{CN})_{6} \cdot 3 \mathrm{H}_{2} \mathrm{O}\right)$, solution $\mathrm{pHs}$ (acid and basic) and reaction times ( $3 \mathrm{~h}$ and $6 \mathrm{~h}$ ). The synthesized materials were thoroughly characterized by transmission electron microscopy and it was found that,

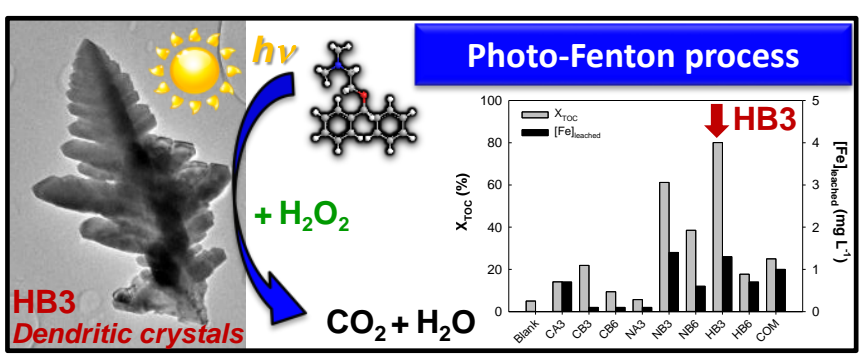
depending on the synthesis conditions, iron oxide samples with crystalline or with amorphous structures could be obtained. Except for the materials synthesised from $\mathrm{K}_{4} \mathrm{Fe}(\mathrm{CN})_{6} \cdot 3 \mathrm{H}_{2} \mathrm{O}$ and $\mathrm{FeCl}_{3} \cdot 6 \mathrm{H}_{2} \mathrm{O}$ under acidic conditions all the samples show mean particle sizes below $70 \mathrm{~nm}$. The materials were further tested as catalysts for the degradation of $100 \mathrm{mg} \mathrm{I}^{-1}$ diphenhydramine aqueous solutions by the photoFenton process at $25{ }^{\circ} \mathrm{C}, \mathrm{pH}=2.8,100 \mathrm{mg} \mathrm{l}^{-1}$ of catalyst and $16 \mathrm{mM}$ of $\mathrm{H}_{2} \mathrm{O}_{2}$ concentration. The best results in terms of pollutant removal and mineralization extent were obtained with the catalysts prepared from $\mathrm{Fe}\left(\mathrm{NO}_{3}\right)_{3} \cdot 9 \mathrm{H}_{2} \mathrm{O}$ and $\mathrm{K}_{4} \mathrm{Fe}(\mathrm{CN})_{6} \cdot 3 \mathrm{H}_{2} \mathrm{O}$, under basic conditions, after $3 \mathrm{~h}$ of synthesis reaction time (complete degradation of diphenhydramine and total organic carbon removal higher than $60 \%$ after $60 \mathrm{~min}$ of reaction). Leaching of iron species from these catalysts was measured below $1.5 \mathrm{mg} \mathrm{I}^{-1}$, a value complying with European Union Directives.
\end{abstract}

Keywords: iron oxide; hydrothermal method; iron precursors; transmission electron microscopy; photoFenton.

\section{Introduction}

In the last decade, nanomaterials have been gaining increasing attention due to their unique properties when compared with those of the bulk materials. The progress achieved on the synthesis of inorganic 
nanostructures, in particular iron oxide nanoparticles, has been accompanied by the parallel exploitation of these systems in various fields, such as biology, medicine and environmental technology (Mornet et al., 2004; Xu et al., 2012). Several types of iron oxides exist in nature, such as $\alpha-\mathrm{Fe}_{2} \mathrm{O}_{3}$, $\gamma-\mathrm{Fe}_{2} \mathrm{O}_{3}$ and $\mathrm{Fe}_{3} \mathrm{O}_{4}$, and can be prepared in the laboratory using different methods such as coprecipitation (Miao et al., 2011), thermal decomposition (Zhu et al., 2011) and hydrothermal synthesis (Tadic et al., 2011). The application of this type of materials as catalysts in water clean-up based on hydrogen peroxide advanced oxidation processes (AOPs) has attracted increasing attention due to their high activity, surface area, uniform pore size distribution and stability (Hou et al., 2014; Zhao et al., 2013). AOPs are known as relatively low cost, easy to operate and effective options for water purification and wastewater treatment, and they can be coupled with biological or traditional physicochemical processes in order to design cost-effective solutions. Among the existing AOPs, the Fenton process (named after the Fenton's reaction following the 1894 studies of Henry Fenton (Fenton 1894)) consists on the production of highly reactive hydroxyl radicals $\left(\mathrm{HO}^{\circ}\right)$ from a mixture of hydrogen peroxide $\left(\mathrm{H}_{2} \mathrm{O}_{2}\right)$ and $\mathrm{Fe}^{2+}$ ions at acidic $\mathrm{pHs}$ (2.5-3.0). This process can be assisted with ultraviolet and/or visible light (known as the photo-Fenton process) with the aim to accelerate the regeneration/reduction of $\mathrm{Fe}^{3+}$ into $\mathrm{Fe}^{2+}$ and restart the normal cycle of the Fenton reaction. In fact, the photo-Fenton process has proven to be a promising alternative for the degradation of a large number of hazardous water pollutants (Herney-Ramirez et al., 2010). Nevertheless, this process has some disadvantages such as the production of sludge, as well as the difficult recovery of the catalyst which is often mandatory because the maximum dissolved iron concentration allowed in European Union standards for discharge of treated waters is $2.0 \mathrm{mg} \mathrm{I}^{-1}$ (as for example in the Portuguese legislation, Decreto-Lei 236/98), while for drinking water is $0.2 \mathrm{mg} \mathrm{l}^{-1}$ (EU Council Directive 98/83/EC 1998). This is the main reason that drove the development of heterogeneous catalytic systems for photo-Fenton, with a special emphasis being given to iron oxide supported catalysts (Liu and You, 2013; Shih et al., 2013; Silva et al., 2012).

In this work, iron oxide materials were synthesized by a simple and rapid hydrothermal route and tested for the degradation of the emerging pharmaceutical pollutant diphenhydramine (DP) by the photoFenton process, aiming to understand the influence of synthesis parameters (iron precursor, $\mathrm{pH}$ and reaction time) on the characteristics of the synthesized materials and related catalytic activity and stability.

\section{Experimental}

\subsection{Reagents}

Iron (III) chloride hexahydrate $\left(\mathrm{FeCl}_{3} \cdot 6 \mathrm{H}_{2} \mathrm{O},>99.0 \%\right)$, iron (III) nitrate nonahydrate $\left(\mathrm{Fe}\left(\mathrm{NO}_{3}\right)_{3} \cdot 9 \mathrm{H}_{2} \mathrm{O}\right.$, 98 wt.\%), potassium hexacyanoferrate(II) trihydrate $\left(\mathrm{K}_{4} \mathrm{Fe}(\mathrm{CN})_{6} \cdot 3 \mathrm{H}_{2} \mathrm{O}, 98.5 \mathrm{wt} \%\right)$, diphenhydramine hydrochloride (2-(diphenylmethoxy)- $\mathrm{N}, \mathrm{N}$-dimethylethylamine hydrochloride, 99\%), $\mathrm{H}_{2} \mathrm{O}_{2}(30 \% \mathrm{w} / \mathrm{w})$ and 1,10-phenantroline $\left(\mathrm{C}_{12} \mathrm{H}_{8} \mathrm{~N}_{2}\right.$, >99\%), were purchased from Sigma-Aldrich. Ammonia aqueous solution (25 wt.\%) was obtained from Pronolab. All chemicals were used without further purification. Distilled water was used throughout the work.

\subsection{Preparation of iron oxide materials and characterization}

The iron oxide materials were synthesized by a hydrothermal process at $180^{\circ} \mathrm{C}$, adapting the procedures described elsewhere (Polshettiwar et al., 2009; Srivastava et al., 2010). Different metallic precursors $\left(\mathrm{FeCl}_{3} \cdot 6 \mathrm{H}_{2} \mathrm{O}, \mathrm{Fe}\left(\mathrm{NO}_{3}\right)_{3} \cdot 9 \mathrm{H}_{2} \mathrm{O}\right.$ and $\left.\mathrm{K}_{4} \mathrm{Fe}(\mathrm{CN})_{6} \cdot 3 \mathrm{H}_{2} \mathrm{O}\right)$, solution $\mathrm{pHs}$ (acid and basic) and reaction times ( $3 \mathrm{~h}$ and $6 \mathrm{~h}$ ) were considered (as shown in Table 1), aiming to understand the influence of these parameters on the synthesis yield, particle size and morphology. In a typical synthesis procedure, $0.01 \mathrm{~mol}$ of the metallic precursor was dissolved in $50 \mathrm{ml}$ of distilled water. When basic conditions were required for the synthesis, the $\mathrm{pH}$ was adjusted with a $25 \mathrm{wt} . \%$ ammonia aqueous solution, slowly dropping it into the iron solution. The resulting solution was then placed in a Teflon-sealed vessel inside a stainless steel autoclave and maintained at $180^{\circ} \mathrm{C}$ in autogenous pressure during the desired reaction time. At the end of the synthesis method, the autoclave was cooled down to room temperature and the 
obtained products were then recovered by filtration using a $0.45 \mu \mathrm{m}$ cellulose nitrate membrane, washed with water and dried overnight at $40{ }^{\circ} \mathrm{C}$. Dark or light brown/orange powders were obtained depending on the synthesis conditions used. A key for the produced samples and correspondent synthesis conditions is given in Table 1 , as well as the yields obtained in each experiment, calculated according to Equation (1).

Yield $(\%)=\frac{\text { Mass of iron in the nanoparticles }}{\text { Mass of iron in the precursor }} \times 100$

For comparison with the synthesized catalysts, commercial iron oxide nanoparticles (Sigma-Aldrich Ref. 544884 , hereafter referred as COM) were also considered in this work. The textural properties of the synthesized materials, as well as of the commercial sample, were assessed by nitrogen adsorptiondesorption isotherms determined at $77 \mathrm{~K}$ in a Quantachrome NOVA 4200e equipment. Before analysis, all samples were outgassed for $8 \mathrm{~h}$ at $393 \mathrm{~K}$. The apparent surface area was calculated by applying the Brunauer-Emmett-Teller (BET) equation (Brunauer et al., 1938). The samples were also characterized in detail by transmission electron microscopy (TEM), coupled with selected area electron diffraction (SAED) and energy-dispersive X-ray spectrometry (EDXS). These analyses were performed on a JEOL JEM-2100, operating at $200 \mathrm{kV}$, information on the morphologies and particle sizes being obtained.

Table 1. Synthesis conditions and respective yield of iron oxide particles.

\begin{tabular}{|c|c|c|c|c|}
\hline Sample Reference & Precursor & $\mathrm{pH}$ & Time (h) & Yield (\%) \\
\hline CA3 & \multirow{3}{*}{$\mathrm{FeCl}_{3} \cdot 6 \mathrm{H}_{2} \mathrm{O}$} & 1.7 & 3 & 10.8 \\
\hline CB3 & & $9.2^{*}$ & 3 & 68.2 \\
\hline CB6 & & $8.2^{*}$ & 6 & 86.5 \\
\hline NA3 & \multirow{3}{*}{$\mathrm{Fe}\left(\mathrm{NO}_{3}\right)_{3} \cdot 9 \mathrm{H}_{2} \mathrm{O}$} & 1.5 & 3 & 86.3 \\
\hline NB3 & & $8.1^{*}$ & 3 & 53.4 \\
\hline NB6 & & $9.2^{*}$ & 6 & 74.6 \\
\hline HB3 & \multirow{2}{*}{$\mathrm{K}_{4} \mathrm{Fe}(\mathrm{CN})_{6} \cdot 3 \mathrm{H}_{2} \mathrm{O}$} & 8.4 & 3 & 19.9 \\
\hline HB6 & & 8.4 & 6 & 33.1 \\
\hline
\end{tabular}

${ }^{*}$ Addition of ammonia aqueous solution (25\%)

\subsection{Photo-Fenton experiments}

The photo-Fenton degradation of $100 \mathrm{wt} . \%\left(3.40 \times 10^{-4} \mathrm{M}\right)$ of DP aqueous solutions was carried out at room temperature $\left(25^{\circ} \mathrm{C}\right)$ under near-UV/Vis irradiation. The experiments were performed in a quartz cylindrical reactor filled with $7.5 \mathrm{~mL}$ of the pharmaceutical pollutant, with an Heraeus TQ 150 mediumpressure mercury vapour lamp, used as irradiation source, delivering to the photoreactor an amount of irradiance equal to $33 \mathrm{~mW} \mathrm{~cm}^{-2}$ (determined using a UV-Vis spectroradiometer USB2000+, OceanOptics, USA). A DURAN ${ }^{\circledR}$ glass cooling jacket with water recirculation was used to operate in the near-UV/Vis light $(\lambda>350 \mathrm{~nm})$ and to control the temperature. Before turning on the lamp, the suspensions were saturated with an oxygen flow and magnetically stirred for $30 \mathrm{~min}$ to establish adsorption-desorption equilibrium. The time zero for the reaction was defined as the time when the lamp was turned on while $\mathrm{H}_{2} \mathrm{O}_{2}$ was simultaneously added.

The experiments were performed at $\mathrm{pH} 2.8,100 \mathrm{mg} \mathrm{l}^{-1}$ of catalyst and $16 \mathrm{mM}$ of $\mathrm{H}_{2} \mathrm{O}_{2}$ concentration (stoichiometric relatively to the complete mineralization of the pollutant). The operational conditions were selected taking into account the effects of catalyst load, initial reaction $\mathrm{pH}$ and $\mathrm{H}_{2} \mathrm{O}_{2}$ concentration in the degradation of DP obtained in preliminary photo-Fenton experiments.

\subsection{Analytical techniques}

The concentration of DP was measured by high performance liquid chromatography (HPLC) with a Hitachi Elite LaChrom system equipped with a Hydrosphere C18 column. The total organic carbon (TOC) was determined for selected samples using a Shimadzu TOC-5000A analyzer. The $\mathrm{H}_{2} \mathrm{O}_{2}$ concentration was determined by adding $1 \mathrm{ml}$ of a $0.5 \mathrm{M} \mathrm{H}_{2} \mathrm{SO}_{4}$ solution and $0.1 \mathrm{ml}$ of $\mathrm{TiO}\left(\mathrm{SO}_{4}\right)(15$ wt.\% in diluted $\mathrm{H}_{2} \mathrm{SO}_{4}$ ) to $1 \mathrm{ml}$ of the liquid sample, and measuring the respective absorbance at $405 \mathrm{~nm}$ in a 
JASCO V-560 spectrophotometer (Eisenberg, 1943). The total iron concentration was measured at the end of the experiments using a colorimetric method with 1,10-phenantroline, measuring the absorbance at $510 \mathrm{~nm}$ (ISO 6332 1998).

\section{Results and discussion}

\subsection{Catalyst characterization}

Table 1 shows that the highest synthesis yields were obtained using the $\mathrm{FeCl}_{3} \cdot 6 \mathrm{H}_{2} \mathrm{O}$ precursor with an alkaline $\mathrm{pH}(8.2)$ and $6 \mathrm{~h}$ of synthesis at $180{ }^{\circ} \mathrm{C}$, or when using the $\mathrm{Fe}\left(\mathrm{NO}_{3}\right)_{3} \cdot 9 \mathrm{H}_{2} \mathrm{O}$ precursor at the natural solution $\mathrm{pH}(1.5)$ during $3 \mathrm{~h}$ at $180^{\circ} \mathrm{C}$. In both cases, the yield is higher than $86 \%$.

A more detailed analysis reveals that for each precursor the reaction yield is strongly dependent on the $\mathrm{pH}$. The influence of $\mathrm{pH}$ on the reaction yield also depends on the precursor used. When $\mathrm{FeCl}_{3} \cdot 6 \mathrm{H}_{2} \mathrm{O}$ is used as precursor and the synthesis takes place in alkaline conditions the yield is strongly increased: the yield obtained at acidic $\mathrm{pH}$ in $3 \mathrm{~h}$ was the lowest (10.8\% for sample $\mathrm{CA} 3)$, while at basic $\mathrm{pH}$ the yield increased to $68.2 \%$ for a $\mathrm{pH}$ value of 9.2 (sample $\mathrm{CB} 3$ ). When $\mathrm{Fe}\left(\mathrm{NO}_{3}\right)_{3} \cdot 9 \mathrm{H}_{2} \mathrm{O}$ is used as precursor, the reverse occurs in $3 \mathrm{~h}$, i.e., the highest yield was obtained at acidic $\mathrm{pH}$ ( $86.3 \%$ for sample NA3) and the reaction yield decreases at basic $\mathrm{pH}$ ( $53.4 \%$ for sample NB3).

The influence of the reaction time is dramatic, as the yield increases more than $25 \%$ (66\% in the case of sample HB6), regardless of the metallic precursor used, meaning that the formation of the particles is not complete after $3 \mathrm{~h}$ of reaction in all cases.

All the synthesized materials, as well as the commercial sample, presented very low BET surface areas $\left(<20 \mathrm{~m}^{2} \mathrm{~g}^{-1}\right)$. These materials were extensively characterized by TEM. The detailed results will be described in the following and a summary of this analysis is compiled in Table 2.

Table 2. Results obtained from Transmission Electron Microscopy

\begin{tabular}{ccc}
\hline Sample & Mean particle size $(\mathrm{nm})$ & Morphology/crystal habits \\
\hline CA3 & $>2000,100 \times 700$ & Crystalline, blocky and prismatic crystals \\
CB3 & 53 & Crystalline, mainly isometric (octahedral) \\
CB6 & 50 & Crystalline, mainly isometric (octahedral) \\
\hline NA3 & 66 & Mainly amorphous \\
NB3 & 64 & Amorphous and crystalline \\
NB6 & 44 & Crystalline, blocky crystals \\
\hline HB3 & $>1000$ & Dendritic crystals \\
HB6 & $>1000$ & Amorphous and dendritic crystals \\
\hline COM & 29 & Crystalline, isometric \\
\hline
\end{tabular}

Figure 1 shows TEM micrographs of samples CA3, CB3 and CB6. Sample CA3 (Figure 1a) consists of quite large blocky crystals (particle sizes $>2000 \mathrm{~nm}$ ) and smaller prismatic particles (mean particle sizes around $100 \times 700 \mathrm{~nm}$ ). In the prismatic particles a large amount of chlorine was also detected by EDXS. Regarding samples CB3 and CB6 (Figures $1 \mathrm{~b}-\mathrm{c}$ and $1 \mathrm{~d}-\mathrm{f}$, respectively), a uniform size distribution is observed, resulting in isometric rather than irregular nanoparticles. The sample CB6, obtained after $6 \mathrm{~h}$ of synthesis, presents a very clear crystalline structure, which was confirmed by SAED analysis (inset in Figure 1e), in contrast with the structure of sample CB3 shown in Figure 1c with the respective SAED analysis, with less crystallinity. The particle size distribution of samples CB3 and CB6 were also determined from the TEM results and mean particle sizes about $50 \mathrm{~nm}$ were found (Table 2). Regarding sample NA3, which was synthesized under acidic conditions (Table 1), TEM reveals that the nanoparticles are mainly amorphous (Figure 2a), although some particles show clear crystalline structures (Figure $2 \mathrm{~b}$ ), as confirmed by SAED analysis (inset in Figure $2 \mathrm{~b}$ ). The size distribution is uniform and the mean particle size is $66 \mathrm{~nm}$. On the other hand, sample NB3, obtained under basic conditions after $3 \mathrm{~h}$ of reaction, presents a mixture of particles with amorphous structure, Figures $2 \mathrm{c}$ and $2 \mathrm{~d}$, and 
particles with some crystalline order, as shown in Figures $2 \mathrm{e}$ and $2 \mathrm{f}$. The size distribution is also very uniform and a mean particle size of $64 \mathrm{~nm}$ was found.

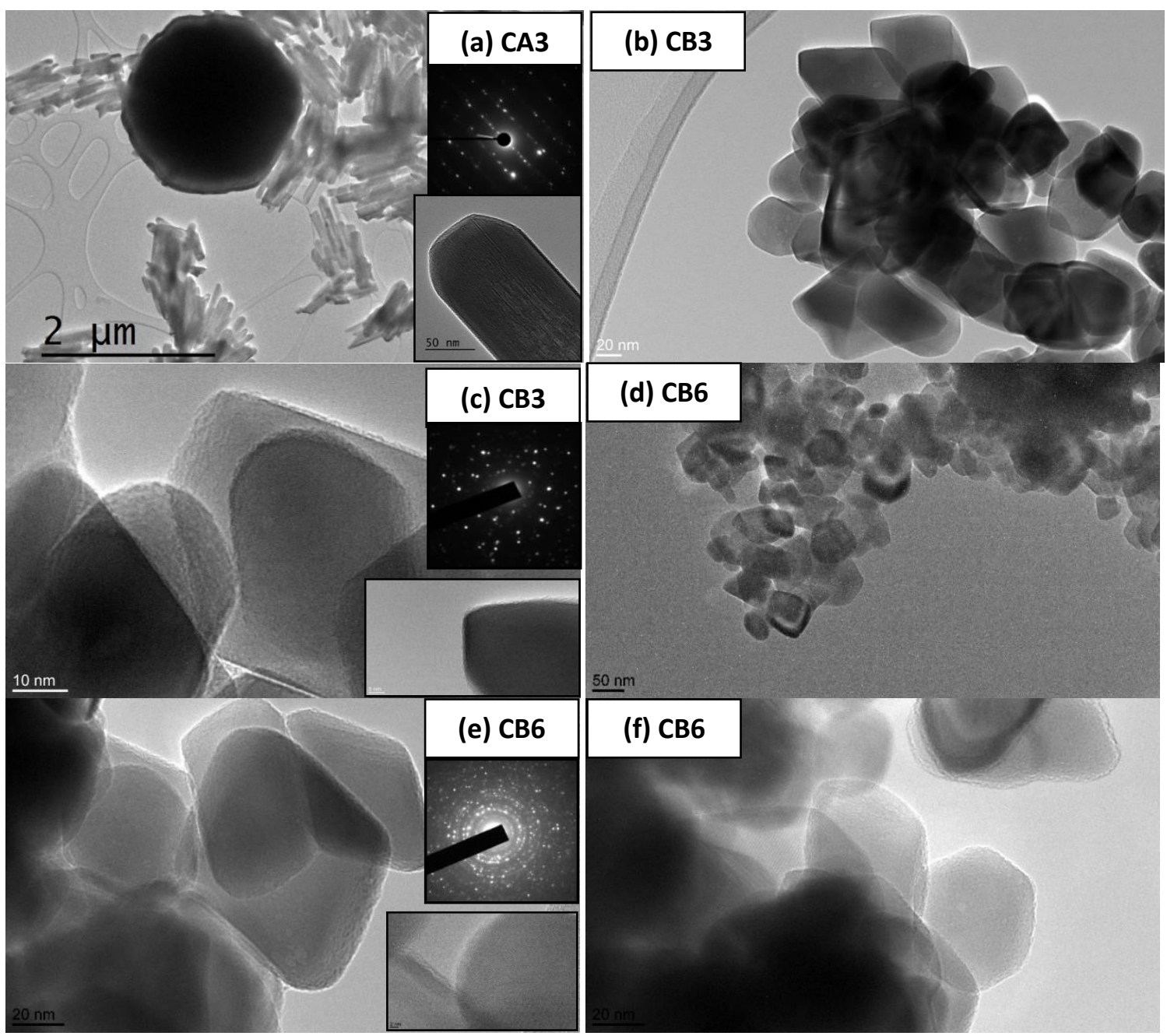

Figure 1. TEM micrographs and SAED patterns of (a) CA3, (b-c) CB3 and (d-f) CB6

Sample NB6 was also synthesized under basic conditions (Table 1), but with a reaction time of $6 \mathrm{~h}$. Again, as observed for the previous samples, the nanoparticles show uniform size distribution (Figure 2g), mainly blocky crystals and clear crystalline structure (Figure $2 \mathrm{~h}$ ), which was confirmed by SAED analysis (inset in Figure $2 \mathrm{~g}$ ). Compared with sample NB3, obtained after $3 \mathrm{~h}$ of synthesis, sample NB6 puts in evidence the influence of the synthesis reaction time on the level of crystallinity of the iron oxide nanoparticles produced from $\mathrm{Fe}\left(\mathrm{NO}_{3}\right)_{3} \cdot 9 \mathrm{H}_{2} \mathrm{O}$, as similarly observed for the nanoparticles produced from $\mathrm{FeCl}_{3} \cdot 6 \mathrm{H}_{2} \mathrm{O}$. The mean particle size obtained for $\mathrm{NB} 6$ was $44 \mathrm{~nm}$, possibly reflecting the higher $\mathrm{pH}$ (9.2) of the initial precursor solution used in the corresponding synthesis experiment, when compared to that of the NB3 (8.1). Figures 3a-c show TEM micrographs of sample HB3. This sample consists of large fragments of dendritic type crystals without impurities. TEM images of the sample HB6 are shown in Figure 3d-f. It is noteworthy that the particles synthesized from $\mathrm{K}_{4} \mathrm{Fe}(\mathrm{CN})_{6} \cdot 3 \mathrm{H}_{2} \mathrm{O}(>1000 \mathrm{~nm})$ are very large compared to the particles synthesized from the other precursors (typically $<70 \mathrm{~nm}$ ). In terms of morphology, sample HB6 consists of amorphous structures (Figure $3 \mathrm{~d}$ ), and some dendritic structures (Figure 3e) resulting from the dissociation in water of the $\left[\mathrm{Fe}(\mathrm{CN})_{6}\right]^{4-}$ ion (Polshettiwar et al., 2009): having six equivalent cyanide atoms, the growth of the structure goes along its six crystalographical main directions. From EDXS analysis, it is possible to identify non-reacted precursor, which is in line with the synthesis reaction yield previously reported (Table 1). 
For comparison, the commercial iron oxide sample (COM) was also analysed, revealing clear crystalline structures with isometric shape (Figure 4). For this sample a relatively non-uniform size distribution was observed with a mean particle size of $29 \mathrm{~nm}$.

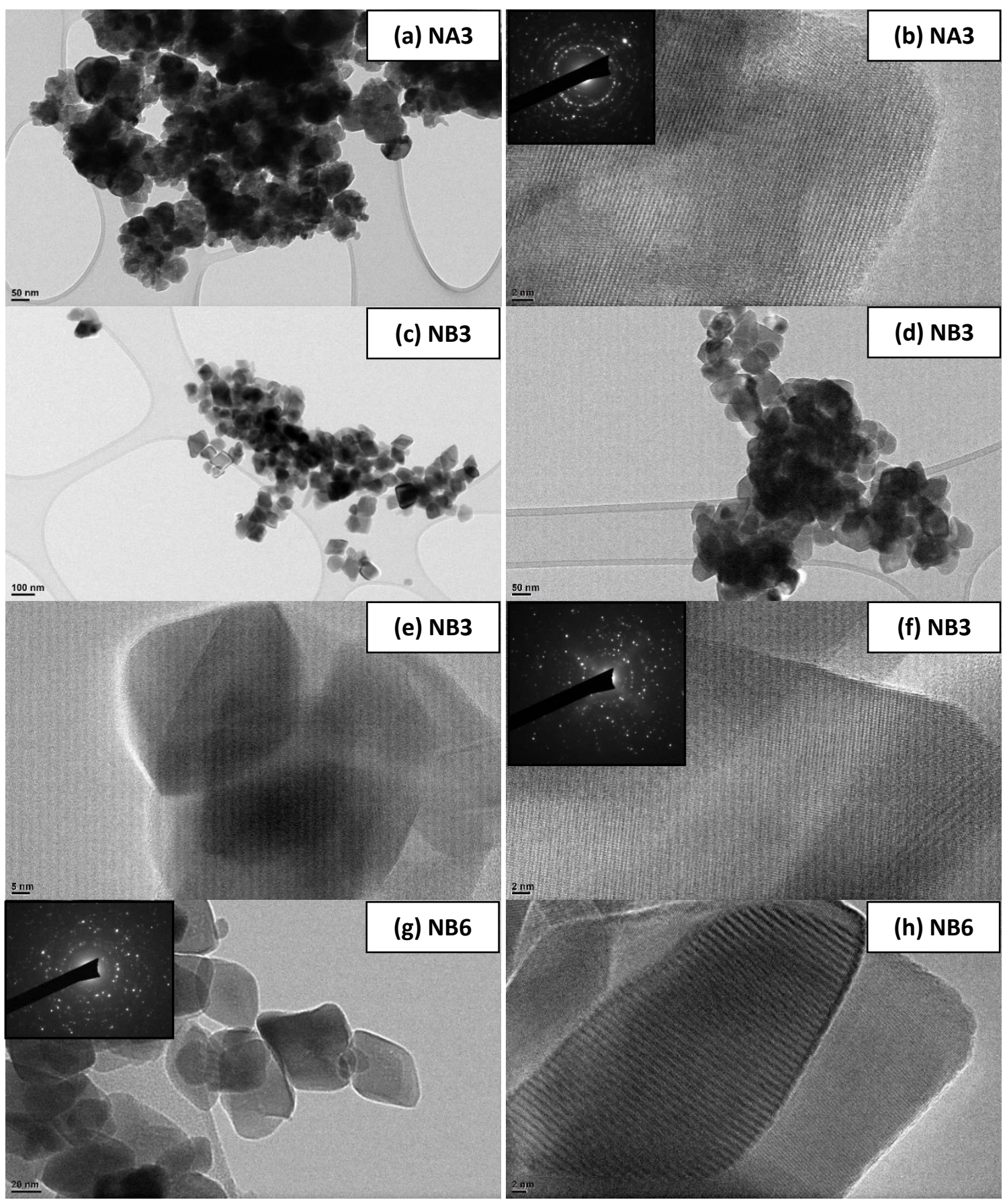

Figure 2. TEM micrographs and SAED patterns of (a-b) NA3, (c-f) NB3 and (g-h) NB6

The morphologies and mean particle sizes obtained from TEM micrographs for the analysed samples are collected in Table 2. From the given data it is concluded that the synthesis reaction time is an important parameter, influencing the crystalline structure of the synthesized nanoparticles. The $6 \mathrm{~h}$ synthesis results in nanoparticles with higher crystallinity when the $\mathrm{Fe}\left(\mathrm{NO}_{3}\right)_{3} \cdot 9 \mathrm{H}_{2} \mathrm{O}$ and $\mathrm{FeCl} \cdot 6 \mathrm{H}_{2} \mathrm{O}$ precursors are used. In the case of the materials synthesized from $\mathrm{K}_{4} \mathrm{Fe}(\mathrm{CN})_{6} \cdot 3 \mathrm{H}_{2} \mathrm{O}$, the size is significantly larger and both amorphous and dendritic type structures are observed. 


\subsection{Photo-Fenton experiments}

The activity of the prepared catalysts during the photo-Fenton runs was evaluated in the photodegradation of DP under near-UV/Vis irradiation (Figure 5).

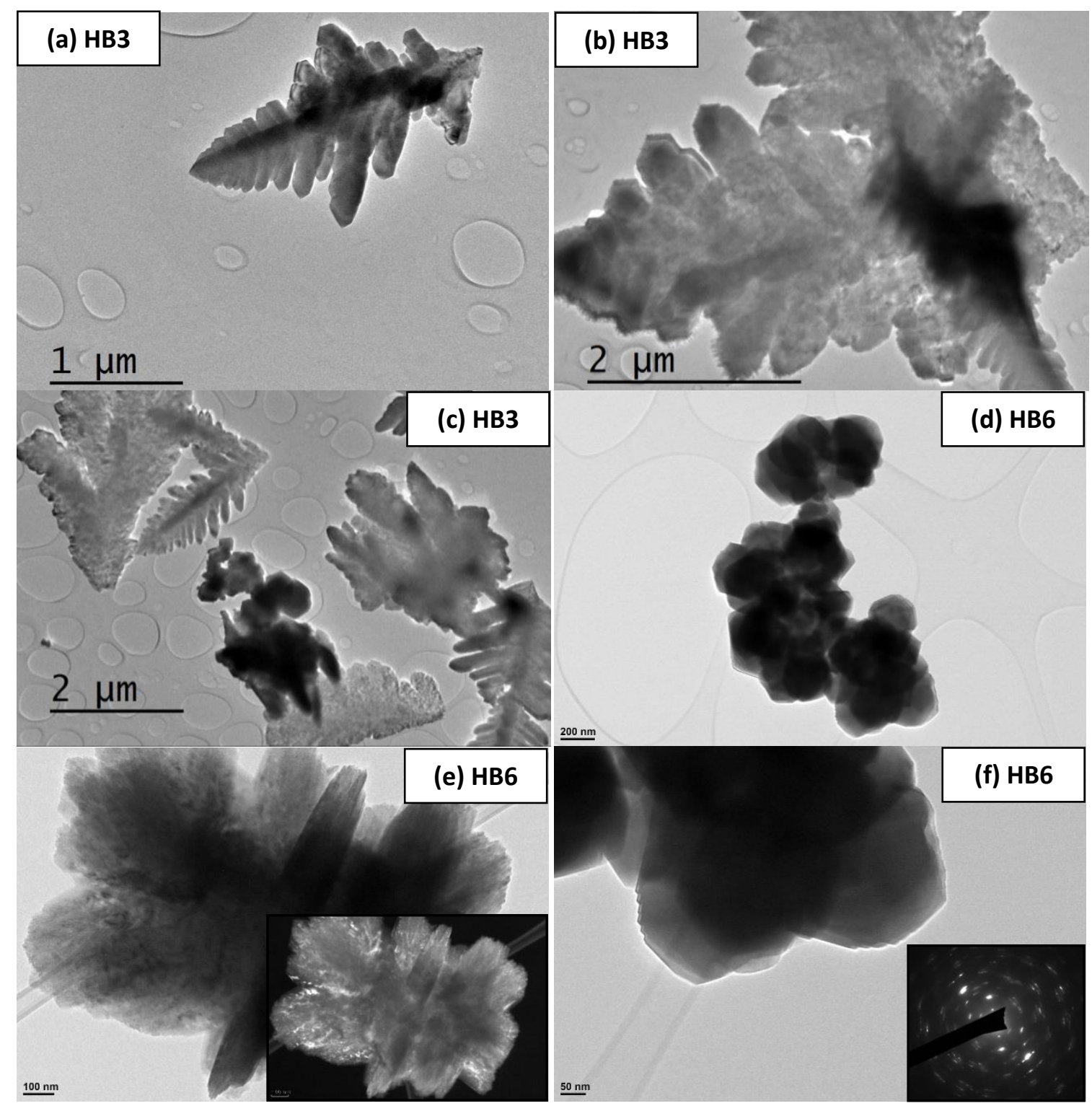

Figure 3. TEM micrographs and SAED patterns of (a-c) HB3 and (d-f) HB6 (inset (e): DF (dark-field) image).

The kinetic parameters of the time profiles, as well as DP conversion (\%), TOC conversion (\%) and the concentration of iron species leached $\left(\mathrm{mg} \mathrm{l}^{-1}\right)$, are gathered in Table 3. The selectivity of the reaction for non-organic compounds $\left(\mathrm{S}_{\mathrm{NOC}}=\mathrm{X}_{\mathrm{TOC}} / \mathrm{X}_{\mathrm{DP}} \times 100\right)$ was also included in Table 3. A blank experiment $\left(\mathrm{H}_{2} \mathrm{O}_{2}\right.$ and UV-Vis) was performed in order to quantify the amount of DP degraded under non-catalytic conditions. In the absence of photocatalyst $57 \%$ of DP conversion and $5 \%$ of TOC removal was registered at the end of the 60 min experiment (Table 3). When the iron oxide catalysts are used, a significant increase of DP conversion (up to $100 \%$ ) and TOC removal (up to $80 \%$ ) is observed for identical time of reaction. The results also show that NB3, HB3 and HB6 promote the highest DP conversion, all reaching complete removal in just $30 \mathrm{~min}$, with pseudo first-order kinetic rate constants $(k)$ of $331.7 \times 10^{-3} \mathrm{~min}^{-1}$, $403.9 \times 10^{-3} \mathrm{~min}^{-1}$ and $278.6 \times 10^{-3} \mathrm{~min}^{-1}$, respectively, which are far better than those obtained with the commercial material, i.e. COM ( $81 \%$ of DP conversion after $30 \mathrm{~min}$ of reaction and $\left.k=54.9 \times 10^{-3} \mathrm{~min}^{-1}\right)$. 
The other iron oxide materials do display a photocatalytic activity for DP conversion however with a lower performance to that of the commercial material (Figure 5a).
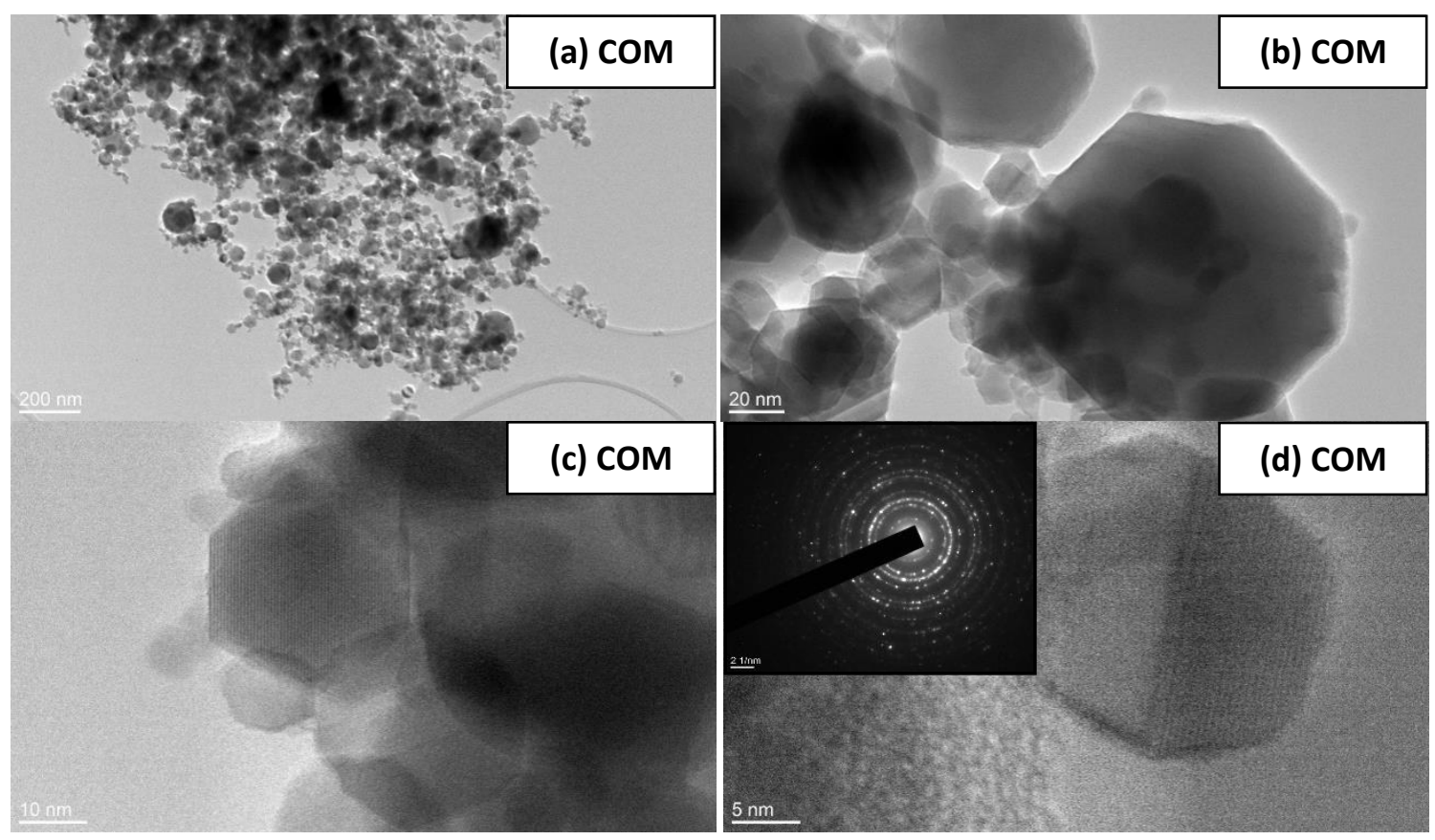

Figure 4. TEM micrographs and SAED patterns of sample COM

The removal of DP from the aqueous solution obtained in the presence of the different iron oxide photocatalysts was paralleled by a similar qualitative $\mathrm{H}_{2} \mathrm{O}_{2}$ consumption (i.e. higher DP conversion results in higher $\mathrm{H}_{2} \mathrm{O}_{2}$ consumption). It should be noted that the magnitude of this consumption is always below the conversion of DP (as shown more clearly in Figure 6b), suggesting that the mineralization (i.e. conversion to only $\mathrm{CO}_{2}$ and $\mathrm{H}_{2} \mathrm{O}$ ) is below $100 \%$ (as shown by $\mathrm{S}_{\mathrm{NOC}}$ values, Table 3 ), thus indicating the presence of intermediate reaction compounds.

Table 3. DP $\left(X_{D P}\right)$ and TOC $\left(X_{T O C}\right)$ conversion, selectivity of the reaction for non-organic compounds $\left(S_{N O C}=X_{T O C} / X_{D P} \times 100\right)$ and leaching of iron species ([Fe $\left.]_{\text {leached }}\right)$ after $60 \mathrm{~min}$ of reaction. The pseudo firstorder kinetic rate constant $(k)$ of DP degradation, the coefficient of variation $\left(k_{\mathrm{cV}}\right)$ and regression coefficient $\left(r^{2}\right)$ are also included

\begin{tabular}{lccccccc}
\hline & $\begin{array}{c}\mathrm{X}_{\mathrm{DP}} \\
(\%)\end{array}$ & $\begin{array}{c}\mathrm{X}_{\mathrm{TOC}} \\
(\%)\end{array}$ & $\begin{array}{c}\mathrm{S}_{\mathrm{NOC}} \\
(\%)\end{array}$ & $\begin{array}{c}{[\mathrm{Fe}]_{\text {leached }}} \\
\left(\mathrm{mg} \mathrm{l}^{-1}\right)\end{array}$ & $\begin{array}{c}\mathrm{k} \\
\left(10^{-3} \mathrm{~min}^{-1}\right)\end{array}$ & $\begin{array}{c}\mathrm{k}_{\mathrm{CV}} \\
(\%)\end{array}$ & $\mathrm{r}^{2}$ \\
\hline Blank & 57 & 5 & 9 & -- & $14.5 \pm 0.8$ & 5.6 & 0.97 \\
CA3 & 76 & 14 & 18 & 0.7 & $24.7 \pm 0.7$ & 2.9 & 0.96 \\
CB3 & 90 & 22 & 24 & 0.1 & $43.4 \pm 1.6$ & 3.8 & 0.995 \\
CB6 & 63 & 9 & 14 & 0.1 & $18.0 \pm 0.8$ & 4.4 & 0.98 \\
NA3 & 68 & 6 & 9 & 0.1 & $21.6 \pm 1.1$ & 5.3 & 0.98 \\
NB3 & 100 & 61 & 61 & 1.4 & $331.7 \pm 25.7$ & 7.5 & 0.995 \\
NB6 & 81 & 39 & 48 & 0.6 & $38.5 \pm 3.7$ & 9.7 & 0.96 \\
HB3 & 100 & 80 & 80 & 1.3 & $403.9 \pm 40.5$ & 10.0 & 0.9997 \\
HB6 & 100 & 18 & 18 & 0.7 & $278.6 \pm 15.2$ & 5.4 & 0.9995 \\
COM & 97 & 25 & 26 & 1.0 & $54.9 \pm 1.1$ & 2.0 & 0.999 \\
\hline
\end{tabular}

Also the TOC conversion (\%) analysis after $60 \mathrm{~min}$ (Table 3 and Figure 6a) is in-line with these findings, the following conversion trend being observed: $\mathrm{HB} 3>\mathrm{NB} 3>\mathrm{NB} 6>\mathrm{COM}>\mathrm{CB} 3>\mathrm{HB} 6>\mathrm{CA} 3>\mathrm{CB} 6>$ NA3. These results indicate that the materials synthesized with both $\mathrm{Fe}\left(\mathrm{NO}_{3}\right)_{3} \cdot 9 \mathrm{H}_{2} \mathrm{O}$ and $\mathrm{K}_{4} \mathrm{Fe}(\mathrm{CN})_{6} \cdot 3 \mathrm{H}_{2} \mathrm{O}$ as precursors, with a synthesis reaction time of $3 \mathrm{~h}$ and under alkaline medium (NB3 and HB3, 
respectively), present a markedly higher catalytic activity for DP degradation than the other materials. This is an interesting result considering that in view of the described characterizations, the crystallinity of the materials is not fully developed for these samples.

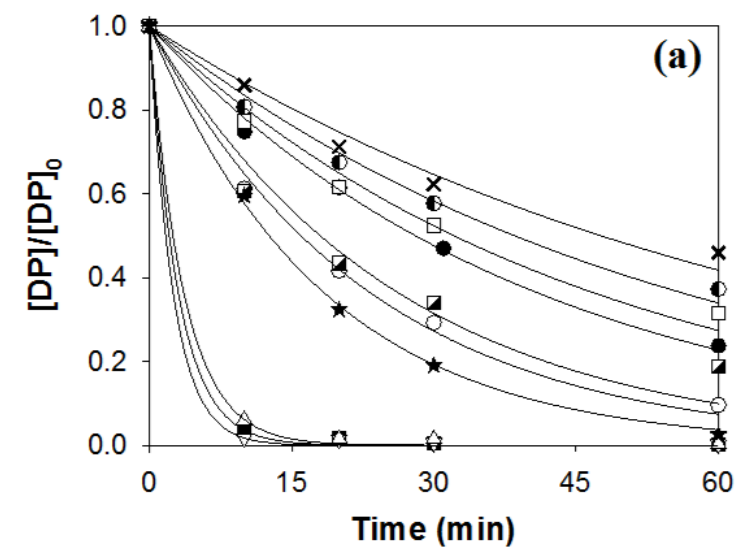

(a)

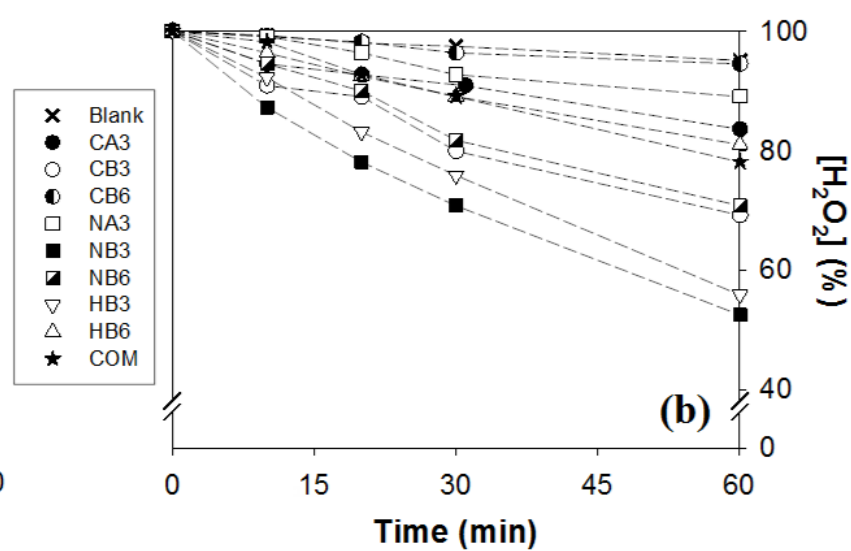

(b)

Figure 5. (a) $[D P] /[D P]_{0}$ as function of time for photo-Fenton experiments and (b) respective $\mathrm{H}_{2} \mathrm{O}_{2}$ conversion as function of time obtained with the different samples

The Fe leached to the solution was also determined for the catalysts at the end of the runs (Table 3 and Figure 6a). NB3 and HB3 lead to the highest leaching of iron species (1.4 and $1.3 \mathrm{mg} \mathrm{I}^{-1}$, respectively) in comparison with the rest of the materials, which all presented values lower than $1 \mathrm{mg} \mathrm{l}^{-1}$. Therefore, it can be assured that all the prepared catalysts present values below the maximum dissolved iron concentration allowed in European Union standards for discharge of treated waters $\left(2.0 \mathrm{mg}^{-1}\right)$.

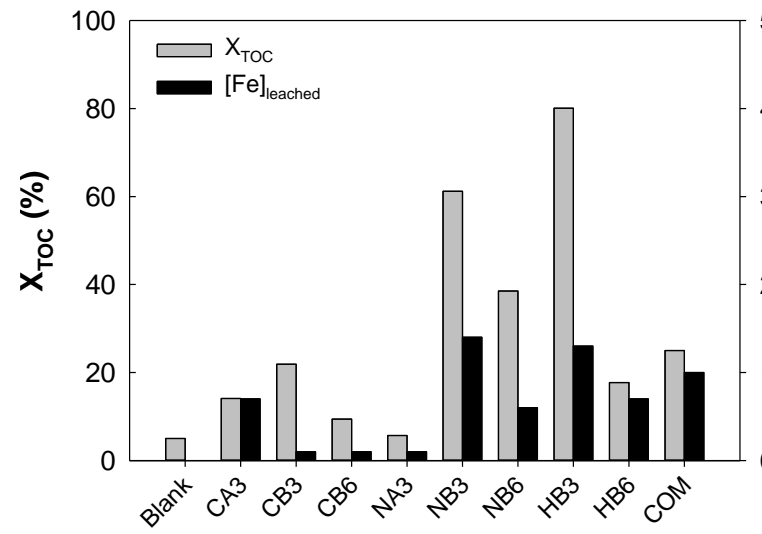

(a)

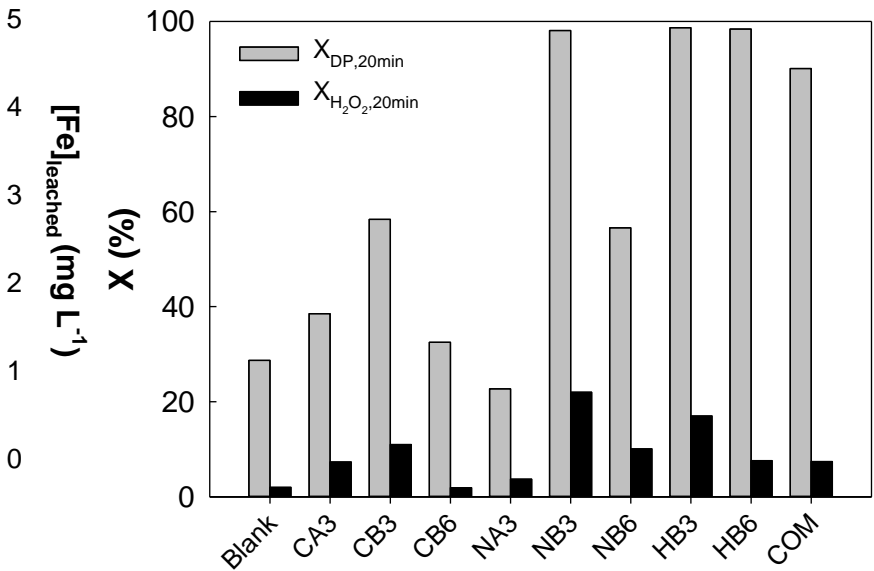

(b)

Figure 6. (a) TOC conversion ( $\left.X_{\text {TOC }}\right)$ and concentration of iron species leached ([Fe $\left.]_{\text {leached }}\right)$ at the end of the photo-Fenton experiments ( $60 \mathrm{~min}$ ); and (b) DP and $\mathrm{H}_{2} \mathrm{O}_{2}$ conversions ( $X$ ) after 20 min of reaction performed with the different samples

\section{Conclusions}

Iron oxide materials are easily synthesized by a hydrothermal method using affordable iron precursors. The reaction yield is strongly dependent on the precursor used, $\mathrm{pH}$ and synthesis time. The highest yield was obtained in alkaline conditions when $\mathrm{FeCl}_{3} \cdot 6 \mathrm{H}_{2} \mathrm{O}$ was used as precursor, and in acidic conditions in 
the case of $\mathrm{Fe}\left(\mathrm{NO}_{3}\right)_{3} \cdot 9 \mathrm{H}_{2} \mathrm{O}$. Morphology/crystal habits was also dependent on these conditions, namely: (i) for $\mathrm{FeCl}_{3} \cdot 6 \mathrm{H}_{2} \mathrm{O}$ : crystalline blocky and prismatic crystals were obtained at low $\mathrm{pH}$, and crystalline, mainly isometric (octahedral), at basic $\mathrm{pH}$; (ii) for $\mathrm{Fe}\left(\mathrm{NO}_{3}\right)_{3} \cdot 9 \mathrm{H}_{2} \mathrm{O}$ : mainly amorphous at acidic $\mathrm{pH}$ while crystalline blocky crystals were also observed at basic $\mathrm{pH}$; and (iii) for $\mathrm{K}_{4} \mathrm{Fe}(\mathrm{CN})_{6} \cdot 3 \mathrm{H}_{2} \mathrm{O}$ : mainly dendritic crystals at basic $\mathrm{pH}$. The catalyst consisting of dendritic crystals has the highest photocatalytic activity, when assessing both pollutant removal and mineralization, and an acceptable leaching of iron species which complies with European Union Directives.

\section{Acknowledgements}

Fundação para a Ciência e a Tecnologia (FCT) and the Slovenian Ministry of Higher Education, Science and Technology. FCT and FEDER through project PEst-C/EQB/LA0020/2013 under Programme COMPETE, and by QREN, ON2 and FEDER through project NORTE-07-0124-FEDER-0000015. AMTS acknowledges FCT Investigator 2013 (IF/01501/2013), the European Social Fund and the Human Potential Operational Programme, and LMPM the FCT grant SFRH/BPD/88964/2012.

\section{References}

Brunauer S., Emmett P.H. and Teller E. (1938), Adsorption of gases in multimolecular layers, Journal of the American Chemical Society, 60, 309-319.

Eisenberg G. (1943), Colorimetric Determination of hydrogen peroxide, Industrial \& Engineering Chemistry Analytical Edition, 15, 327-328.

EU Council Directive 98/83/EC (1998): On the quality of water intended for human consumption, Official Journal of the European Communities L330.

Fenton H.J.H. (1894), LXXIII.-Oxidation of tartaric acid in presence of iron, Journal of the Chemical Society, Transactions, 65, 899-910

Herney-Ramirez J., Vicente M.A. and Madeira L.M. (2010), Heterogeneous photo-Fenton oxidation with pillared clay-based catalysts for wastewater treatment: A review, Applied Catalysis B: Environmental, 98, 10-26.

Hou L., Zhang Q., Jerome F., Duprez D., Zhang H. and Royer S. (2014), Shape-controlled nanostructured magnetitetype materials as highly efficient Fenton catalysts, Applied Catalysis B:Environmental, 144, 739-749.

ISO 6332 (1998), Water Quality - Determination of Iron - Spectrometric Method Using 1,10-Phenanthroline. International Organization for Standardization, Geneva, Switzerland.

Liu T. and You H. (2013), Photoassisted Fenton-like degradation of polyacrylamide aqueous solutions using iron oxide/ $/ \mathrm{TiO}_{2} / \mathrm{Al}_{2} \mathrm{O}_{3}$ heterogeneous catalysts, Reaction Kinetics Mechanisms and Catalysis, 109, 233-246.

Miao H., Li J., Lin Y.Q., Liu X.D., Zhang Q.M. and Fu J. (2011), Characterization of $\mathrm{Y}^{-} \mathrm{Fe}_{2} \mathrm{O}_{3}$ nanoparticles prepared by transformation of $\alpha-\mathrm{FeOOH}$, Chinese Science Bulletin, 56, 2383-2388.

Mornet S., Vasseur S., Grasset F. and Duguet E. (2004), Magnetic nanoparticle design for medical diagnosis and therapy, Journal of Materials Chemistry, 14, 2161-2175.

Polshettiwar V., Baruwati B. and Varma R.S. (2009), Self-assembly of metal oxides into three-dimensional nanostructures: synthesis and application in catalysis, ACS Nano 3, 728-736.

Shih Y-J., Ho C-H. and Huang Y-H. (2013), Photo-Fenton oxidation of azo dye reactive black b using an immobilized iron oxide as heterogeneous catalyst, Water Environment Research, 85, 340-345.

Silva A.M.T., Herney-Ramirez J., Söylemez U. and Madeira L.M. (2012), A lumped kinetic model based on the Fermi's equation applied to the catalytic wet hydrogen peroxide oxidation of Acid Orange 7, Applied Catalysis B: Environmental, 121-122, 10-19.

Srivastava M., Ojha A.K., Chaubey S., Singh J., Sharma P.K. and Pandey A.C. (2010), Investigation on magnetic properties of $\alpha-\mathrm{Fe}_{2} \mathrm{O}_{3}$ nanoparticles synthesized under surfactant-free condition by hydrothermal process, Journal of Alloys and Compounds, 500, 206-210.

Tadic M., Citakovic N., Panjan M., Stojanovic Z., Markovic D. and Spasojevic V. (2011), Synthesis, morphology, microstructure and magnetic properties of hematite submicron particles, Journal of Alloys and Compounds, 509, 7639-7644. 
Xu P., Zeng G.M., Huang D.L., Feng C.L., Hu S., Zhao M.H., Lai C., Wei Z., Huang C., Xie G.X. and Liu Z.F. (2012), Use of iron oxide nanomaterials in wastewater treatment: A review, Science of The Total Environment, 424, 1-10.

Zhao Y., Pan F., Li H., Niu T., Xu G. and Chen W. (2013), Facile synthesis of uniform alpha- $\mathrm{Fe}_{2} \mathrm{O}_{3}$ crystals and their facet-dependent catalytic performance in the photo-Fenton reaction, Journal of Materials Chemistry A, 1, 7242-7246.

Zhu Y., Jiang F.Y., Chen K.X., Kang F.Y. and Tang Z.K. (2011), Size-controlled synthesis of monodisperse superparamagnetic iron oxide nanoparticles, Journal of Alloys and Compounds, 509, 8549-8553. 